\title{
Determination of Quality Characteristic of Biscuits Including Ground Yellow Poppy Seed as Fat Replacer
}

\author{
Seda YALCIN *1 \\ ${ }^{1}$ Afyon Vocational School, Food Technology Programme, Afyon Kocatepe University, Afyon, Turkey
}

Received: 03 May 2017 - Revised: 12 October 2017 - Accepted: 13 November 2017

\begin{abstract}
In this study, fat was replaced by ground yellow poppy seed in biscuit formulation for producing low fat biscuit and the changes in physical characteristics, color values and total phenolic content of biscuits with fat replacement were investigated. Fat replacement caused an increase in weight and spread ratio of biscuits, indicating improved quality. Lower $\mathrm{L}^{*}$ values, higher $\mathrm{a}^{*}$ and $\mathrm{b}^{*}$ values were obtained for biscuits including ground yellow poppy seed. Total phenolic content of biscuits increased gradually as ground yellow poppy seed level in biscuits increased.
\end{abstract}

Keywords: poppy seed, fat replacer, biscuit

\section{INTRODUCTION}

Poppy (papaver somniferum) is cultivated as an annual crop in China, India and Turkey. Poppy seeds had high amount of $\mathrm{P}, \mathrm{K}, \mathrm{Ca}, \mathrm{Mg}, \mathrm{Na}$ and Fe. $\alpha$-tocopherol, $\beta$-tocopherol and $\delta$ tocopherol contents of poppy seeds were in the range of $26.8-37.2 \mathrm{ppm}, 309.5-567.3 \mathrm{ppm}$, and 6.1-18.6 ppm, respectively. Poppy seeds had also palmitic acid, stearic acid, oleic acid, linoleic acid and linolenic acid. Linoleic acid was found at high level in poppy seeds [1]. Bozan and Temelli [2] reported that total phenolic content of poppy seed was $930 \mathrm{mg} / 100 \mathrm{~g}$. Emir et al. [3] investigated sensory properties, aromatic profiles and consumer preferences of cold pressed poppy seed oils. The authors reported that roasting before cold pressing increased sweet aromatic values and roasted samples were more liked by consumers. The yellow (produced in Afyon) roasted sample was the most preferred (53.55\%) by consumers in all samples (white, yellow, blue).

Fat is an important ingredient responsible for texture, flavor and perception of biscuits [4]. The fats used in biscuit production contain saturated fatty acids at high level which give them the solid consistency. But lower levels of saturated fatty acids are desirable for health reasons [5]. High fat is associated with some diseases (obesity, cancer, cholesterol, heart diseases) [6]. For this reason, fat replacers can be used in biscuit formulation. Sudha et al. [7] investigated the effects of fat replacement on biscuit quality. Fat in the biscuit formulation was

*Corresponding Author E-mail: syalcin@aku.edu.tr 
reduced from $20 \%$ to $10 \%, 8 \%$ and $6 \%$, in the study. It was reported that fat reduction had a negative effect on biscuit texture. When fat was replaced with maltodextrin, biscuit texture improved. Swanson and Munsayac [8] reported that fat replacement with fruit puree reduced cookie spread. Swanson [9] reported that cookies prepared with fat replacers (oatrim, mixedblend, polydextrose) were less fracturable and softer than the control. Adair et al. [10] reported that fat replacement with mungbean paste reduced cookie spread. Tarancón et al. [11] replaced saturated fat with olive oil or sunflower oil in biscuit formulation and investigated the effect of this replacement on sensory characteristics of biscuits. It was reported that biscuits acceptability, when saturated fat replaced by vegetable oils, depended on biscuit fat content. Fat replacement caused a decrease in acceptability in low fat biscuits (10.6\%), while it did not cause significant changes in acceptability in high fat biscuits (15.6\%). Most of consumers (48\%) preferred shortening biscuits, while $24 \%$ of consumers preferred both olive oil and shortening biscuits at high fat content and $28 \%$ of consumers preferred vegetable oil biscuits. Tarancón et al. [12] reported that the information on the labels of the biscuits including olive oil or sunflower oil increased the perception of healthiness and resulted in higher hedonic expectations among the consumers than that on the labels of biscuits including dairy shortening. Biguzzi et al. [13] investigated the effect of sugar and fat reduction on perception and liking of biscuits. It was reported that fat reduction was more acceptable than sugar reduction in biscuits. Zoulias et al. [4] replaced 50\% of fat by carbohydrate based or protein based fat replacers and investigated the effect of this replacement on textural properties of cookies. It was reported that fat replacement increased hardness and brittleness of cookies.

There is no study about utilization of ground yellow poppy seed in biscuit formulation for reducing fat content in biscuit, in the literature. In this study, fat was replaced by ground yellow poppy seed in biscuits at the levels of $25 \%, 50 \%, 75 \%$ or $100 \%$ and the effects of fat replacement on physical characteristics and total phenolic content of biscuits were investigated.

\section{MATERIAL and METHODS}

\subsection{Materials}

Soft wheat flour was obtained from Önem Food Inc. (Ankara, Turkey). Biscuit ingredients were purchased from local market. Ground yellow poppy seed was purchased from local producer (Afyon).

\subsection{Preparation of Biscuits}

Biscuits were prepared using the method of AACC 2000 [14] with slight modifications. For the preparation of low fat biscuits, fat content in the biscuit formulation was reduced by $25 \%, 50 \%, 75 \%$ and $100 \%$. Fat, sugar power, sodium bicarbonate, salt, brown sugar and non fat dry milk were mixed in a laboratory dough mixer (Essenso, Turkey). Then ammonium bicarbonate and water were added to cream and mixed again. Then flour was added to mix. After mixing, the dough was taken and sheeted to a thickness of $6.9 \mathrm{~mm}$. The dough was cut into circular shape using $59.5 \mathrm{~mm}$ diameter cutter on aluminum baking tray. They were baked at $200^{\circ} \mathrm{C}$ for $11 \mathrm{~min}$. The baked biscuits were cooled to room temperature before analysis.

\subsection{Weight and Geometry of Biscuits}

Weight of biscuits was measured with weighing balance. Thickness and diameter of biscuits were measured with caliper. Spread ratio of biscuits was calculated by dividing diameter by thickness of biscuits. All experiments were performed in duplicates. 


\subsection{Color Properties of Biscuits}

The color measurement $\left(\mathrm{L}^{*}, \mathrm{a}^{*}, \mathrm{~b}^{*}\right)$ was carried out in duplicate on biscuits using the $\mathrm{L}^{*} \mathrm{a}^{*} \mathrm{~b}^{*}$ color system, where $\mathrm{L}^{*}$ is lightness, $\mathrm{a}^{*}$ is redness, and $\mathrm{b}^{*}$ is yellowness. The instrument used was a X-rite (USA).

\subsection{Determination of Total Phenolic Content in Biscuits}

Extraction of samples was carried out according to the method of Awika et al. [15]. Samples $(1 \mathrm{~g})$ were mixed with $10 \mathrm{~mL}$ of $1 \% \mathrm{HCL}$ in methanol for $1 \mathrm{~h}$ and centrifuged at 3000 rpm for 20 min (DAIHAN Scientific Co., Ltd., WiseSpin ${ }^{\circledR}$ CF-10 Microcentrifuge, Korea). The supernatant was used for determination of total phenolic content.

Total phenolic content of biscuits was determined according to the Folin-Ciocalteu method reported by Li et al. [16]. Sample extract $(0.2 \mathrm{~mL})$ was added to $0.8 \mathrm{~mL}$ diluted FolinCiocalteu reagent (1/10) and waited for $3 \mathrm{~min}$. Then $2 \mathrm{~mL}$ of sodium carbonate solution $(15 \%$, $\mathrm{w} / \mathrm{v}$ ) was added to mixture. After addition of $2 \mathrm{~mL}$ destile water, the mixture was vortexed and kept in darkness at room temperature for $1 \mathrm{~h}$. The absorbance was measured at $760 \mathrm{~nm}$ using UV-Vis spectrophotometer (Optizen pop, Korea). Gallic acid $(0-0.5 \mathrm{mg} / \mathrm{mL})$ prepared in methanol, was used as standard. The results were expressed as mg gallic acid (GAE) /g sample (dry basis). The analysis was performed in duplicate.

\subsection{Statistical Analysis}

Data related to weight, biscuit geometry, color properties and total phenolic content of the biscuits were statistically evaluated by one-way analysis of variance procedure. Duncan test was applied to compare mean values.

\section{RESULTS and DISCUSSIONS}

\subsection{Biscuit Quality Characteristics}

The effects of replacing of fat with ground yellow poppy seed on biscuit weight, thickness, diameter and spread ratio are given in Table 1. Fat replacement produced a significant change $(\mathrm{p}<0.05)$ in quality properties of biscuits. The moisture content of biscuits containing ground yellow poppy seed ranged from $5.85 \%$ to $7.19 \%$.

Biscuits containing ground yellow poppy seed $(50 \%, 75 \%, 100 \%)$ showed significantly higher weights as compared to control biscuit. No significant differences were seen in weights between biscuit with $25 \%$ fat replacement and biscuit with $50 \%$ fat replacement or control biscuit. Biscuits containing ground yellow poppy seed (75\% and $100 \%)$ had significantly higher diameter than control biscuit. Diameters of biscuits containing ground yellow poppy seed (25\% and 50\%) were not significantly different from that of control biscuit. Diameter of biscuit with $75 \%$ fat replacement was not significantly different from that of biscuit with $100 \%$ fat replacement.

There was significant decrease in the thickness of biscuits from $15.4 \mathrm{~mm}$ to $11.4 \mathrm{~mm}$ with fat reduction. Biscuits containing ground yellow poppy seed $(75 \%$ and $100 \%)$ had a significantly lower thickness than control biscuit. No significant differences were seen in thickness between control biscuit, biscuit with $25 \%$ fat replacement and biscuit with $50 \%$ fat replacement and between biscuit with $25 \%$ fat replacement, biscuit with $50 \%$ fat replacement and biscuit with $75 \%$ fat replacement.

Spread ratio of biscuit, which is important quality parameter, increased with the fat replacement. Biscuits containing ground yellow poppy seed (75\% and 100\%) showed significantly higher levels in comparison to the control biscuit. Spread ratio of control biscuit was not significantly different from that of biscuit with $25 \%$ fat replacement and that of biscuit with $50 \%$ fat replacement. No significant difference was observed between spread ratios of 
biscuit with $25 \%$ fat replacement, biscuit with $50 \%$ fat replacement and biscuit with $75 \%$ fat replacement. The spread ratio of biscuit containing ground yellow poppy seed was found to be the highest (5.65). The similar results were also observed by Hadnadev et al. [17]. The authors investigated functionality of semi-plastic shortenings based on starch sodium octenyl succinate stabilized oil-in water emulsions as fat replacers in cookies. It was reported that spread ratio of cookie increased with the substitution of fat with vegetable oil (in the form of $70 \%$ oil-in-water emulsion).

Table 1. Physical parameters of biscuit samples.

\begin{tabular}{lllll}
\hline $\begin{array}{l}\text { Level of fat } \\
\text { replacement }\end{array}$ & Weight $(\mathrm{g})$ & Diameter $(\mathrm{mm})$ & Thickness $(\mathrm{mm})$ & $\begin{array}{l}\text { Spread ratio } \\
(\mathrm{D} / \mathrm{T})\end{array}$ \\
\hline $0 \%$ & $17.8 \pm 0.2^{\mathrm{d}}$ & $60.5 \pm 1.0^{\mathrm{b}}$ & $15.4 \pm 0.4^{\mathrm{a}}$ & $3.93 \pm 0.17^{\mathrm{c}}$ \\
$25 \%$ & $18.5 \pm 0.2^{\mathrm{cd}}$ & $60.8 \pm 0.3^{\mathrm{b}}$ & $14.4 \pm 0.9^{\mathrm{ab}}$ & $4.25 \pm 0.25^{\mathrm{bc}}$ \\
$50 \%$ & $19.5 \pm 0.3^{\mathrm{c}}$ & $61.7 \pm 0.5^{\mathrm{b}}$ & $13.8 \pm 0.4^{\mathrm{ab}}$ & $4.48 \pm 0.08^{\mathrm{bc}}$ \\
$75 \%$ & $20.7 \pm 0.2^{\mathrm{b}}$ & $63.5 \pm 0.6^{\mathrm{a}}$ & $13.0 \pm 0.0^{\mathrm{b}}$ & $4.88 \pm 0.05^{\mathrm{b}}$ \\
$100 \%$ & $22.9 \pm 1.0^{\mathrm{a}}$ & $63.9 \pm 0.1^{\mathrm{a}}$ & $11.4 \pm 0.9^{\mathrm{c}}$ & $5.65 \pm 0.44^{\mathrm{a}}$ \\
\hline
\end{tabular}

Not: Values are means \pm standard deviation of two replicates. Within the same column, values with the same letter are not statistically different according to Duncan test $(\mathrm{p}<0.05)$.

\subsection{Color Properties of Ground Biscuits}

Color properties $\left(\mathrm{L}^{*}, \mathrm{a}^{*}, \mathrm{~b}^{*}\right)$ of biscuits containing different fat contents are given in Table 2. Fat reduction in biscuits lead to significant decrease in $L^{*}$ (lightness) where a significant increase in $a^{*}$ (redness) and $b^{*}$ (yellowness). L* values (lightness) of biscuits containing ground yellow poppy seed were lower than those of control biscuit. This indicates that low fat content may act as a plasticizer covering all powder ingredient which caused high amount of sugar involved in Maillard reaction [17]. Significant increases in a* values of biscuits containing ground yellow poppy seed compared to that of control biscuit were observed. $\mathrm{b}^{*}$ value of control biscuit was not significantly different from that of biscuit with $25 \%$ or $50 \%$ fat replacement. Lara et al.[18] reported that the decrease in $\mathrm{L}^{*}$ and the increase in $\mathrm{a}^{*}$ values is indicator of browning progress.

Table 2. Color properties of biscuit samples.

\begin{tabular}{llll}
\hline Level of fat replacement & $\mathrm{L}^{*}$ & $\mathrm{a}^{*}$ & $\mathrm{~b}^{*}$ \\
\hline $0 \%$ & $71.12 \pm 0.04^{\mathrm{a}}$ & $12.42 \pm 0.11^{\mathrm{e}}$ & $30.60 \pm 0.23^{\mathrm{c}}$ \\
$25 \%$ & $70.33 \pm 0.04^{\mathrm{b}}$ & $12.73 \pm 0.04^{\mathrm{d}}$ & $30.76 \pm 0.33^{\mathrm{c}}$ \\
$50 \%$ & $69.31 \pm 0.08^{\mathrm{c}}$ & $13.11 \pm 0.02^{\mathrm{c}}$ & $31.04 \pm 0.03^{\mathrm{c}}$ \\
$75 \%$ & $68.23 \pm 0.19^{\mathrm{d}}$ & $13.45 \pm 0.03^{\mathrm{b}}$ & $31.60 \pm 0.02^{\mathrm{b}}$ \\
$100 \%$ & $67.49 \pm 0.37^{\mathrm{e}}$ & $13.73 \pm 0.03^{\mathrm{a}}$ & $32.12 \pm 0.06^{\mathrm{a}}$
\end{tabular}

Not: Values are means \pm standard deviation of two replicates. Within the same column, values with the same letter are not statistically different according to Duncan test $(\mathrm{p}<0.05)$.

\subsection{Total Phenolic Content of Biscuits}

Total phenolic content of biscuits are shown in Figure 1. Replacement of fat in biscuits with ground yellow poppy seed lead to significant increase in total phenolic content. Increasing level of ground yellow poppy seed in biscuits increased the total phenolic content from $0.89 \mathrm{mg}$ gallic acid/g sample to $1.22 \mathrm{mg}$ gallic acid/g sample. Phenolic compounds are considered to be major contributors to the antioxidant capacity. These antioxidants have biological activities such as anti-carcinogenic activities [19]. 


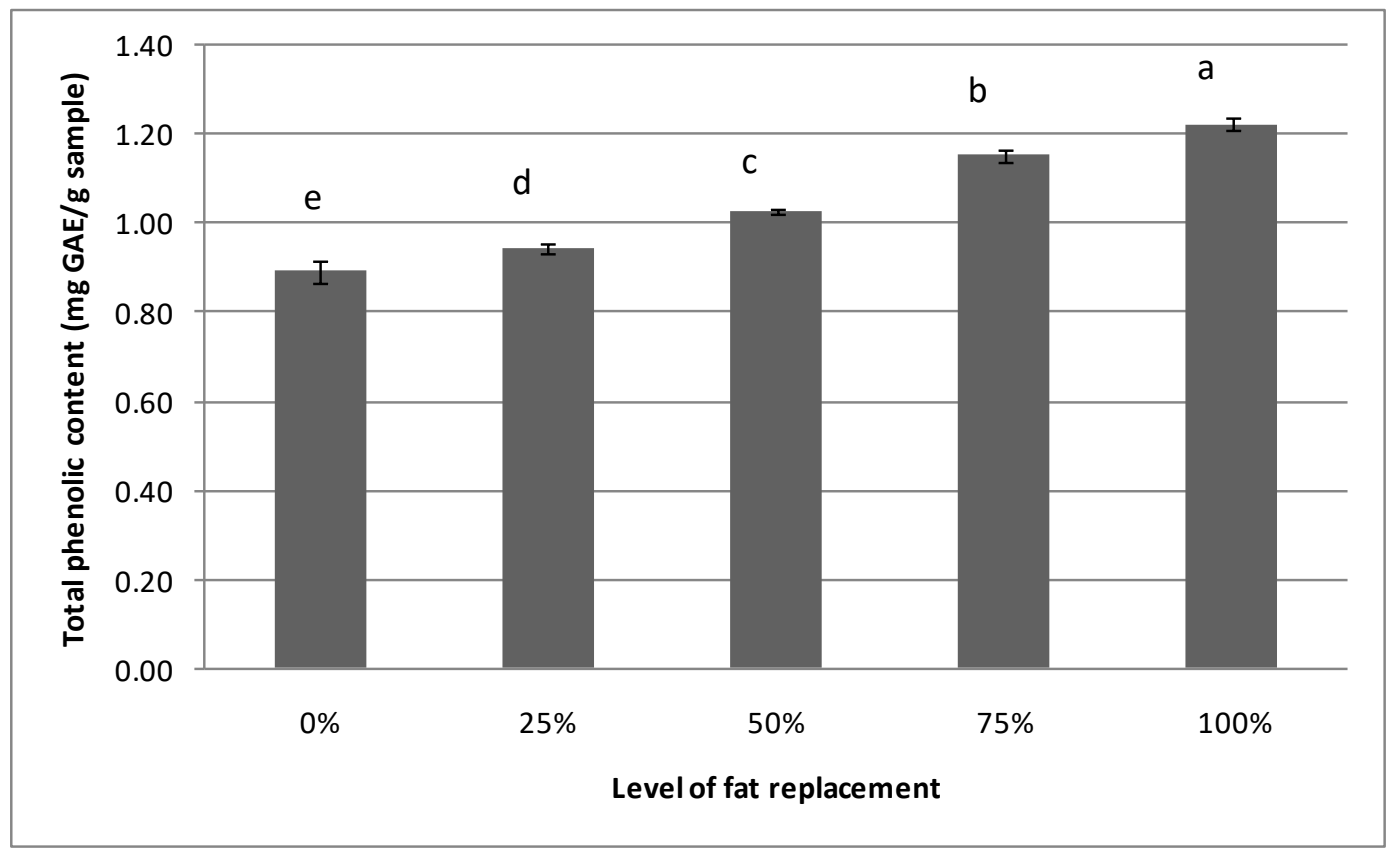

Figure 1. Total phenolic content of biscuit samples. Values not sharing letters were significantly different $(\mathrm{p}<0.05)$ according to Duncan test.

\section{CONCLUSION}

In this study, ground yellow poppy seed at different levels $(25 \%, 50 \%, 75 \%, 100 \%)$ was used in biscuit formulation as fat replacer. Effects of this replacement on weight, spread ratio, color values and total phenolic content of biscuits were investigated.

The replacement of fat in biscuits with ground yellow poppy seed resulted in the increase in weight and spread ratio of biscuits. $L^{*}$ value decreased, while $a^{*}$ and $b^{*}$ values increased with fat replacement in biscuits. Total phenolic contents of biscuits containing ground yellow poppy seed were higher than that of control biscuit. This indicates that healthier biscuits were obtained by replacement of fat with ground yellow poppy seed.

The level of fat replacer (ground yellow poppy seed) affects weight, spread ratio, color values $\left(\mathrm{L}^{*}, \mathrm{a}^{*}, \mathrm{~b}^{*}\right)$ and total phenolic content of biscuits. Weights, spread ratios and total phenolic contents increased with increasing level of ground yellow poppy seed in biscuits, which caused improvement in biscuit quality.

\section{Acknowledgement}

I wish to thank Önem Food Inc. (Ankara, Turkey) for providing soft wheat flour.

\section{Conflict of Interests}

Authors declare that there is no conflict of interests.

\section{REFERENCES}

[1]. Özcan, M. M., \& Atalay, Ç. (2006). Determination of seed and oil properties of some poppy (Papaver somniferum L.) varieties. Grasas y aceites, 57(2), 169-174.

[2]. Bozan, B., \& Temelli, F. (2008). Chemical composition and oxidative stability of flax, safflower and poppy seed and seed oils. Bioresource Technology, 99(14), 6354-6359.

[3]. Emir, D. D., Güneșer, O., \& Y1lmaz, E. (2014). Cold pressed poppy seed oils: sensory properties, aromatic profiles and consumer preferences. Grasas y Aceites, 65(3), 029. 
[4]. Zoulias, E. I., Oreopoulou, V., \& Tzia, C. (2002). Textural properties of low-fat cookies containing carbohydrate-or protein-based fat replacers. Journal of Food Engineering, 55(4), 337-342.

[5]. Tarancón, P., Hernández, M. J., Salvador, A., \& Sanz, T. (2015). Relevance of creep and oscillatory tests for understanding how cellulose emulsions function as fat replacers in biscuits. LWT-Food Science and Technology, 62(1), 640-646.

[6]. Akoh, C. C. (1998). Fat replacers. Food technology, 52(3), 47-53.

[7]. Sudha, M. L., Srivastava, A. K., Vetrimani, R., \& Leelavathi, K. (2007). Fat replacement in soft dough biscuits: Its implications on dough rheology and biscuit quality. Journal of Food Engineering, 80(3), 922-930.

[8]. Swanson, R. B., \& MUNSAYAC, L. J. (1999). Acceptability of fruit purees in peanut butter, oatmeal, and chocolate chip reduced-fat cookies. Journal of the American Dietetic Association, 99(3), 343-345.

[9]. Swanson, R. B. (1998). Acceptability of reduced-fat peanut butter cookies by school nutrition managers. Journal of the American Dietetic Association, 98(8), 910-912.

[10]. Adair, M., Knight, S., \& Gates, G. (2001). Acceptability of peanut butter cookies prepared using mungbean paste as a fat ingredient substitute. Journal of the American Dietetic Association, 101(4), 467-469.

[11]. Tarancón, P., Salvador, A., Sanz, T., Fiszman, S., \& Tárrega, A. (2015). Use of healthier fats in biscuits (olive and sunflower oil): changing sensory features and their relation with consumers' liking. Food Research International, 69, 91-96.

[12]. Tarancón, P., Sanz, T., Fiszman, S., \& Tárrega, A. (2014). Consumers' hedonic expectations and perception of the healthiness of biscuits made with olive oil or sunflower oil. Food research international, 55, 197-206.

[13]. Biguzzi, C., Schlich, P., \& Lange, C. (2014). The impact of sugar and fat reduction on perception and liking of biscuits. Food Quality and Preference, 35, 41-47.

[14]. Approved methods of the American association of cereal chemists. Amer Assn of Cereal Chemists, 2000.

[15]. Awika, J. M., Rooney, L. W., \& Waniska, R. D. (2004). Properties of 3deoxyanthocyanins from sorghum. Journal of Agricultural and Food Chemistry, 52(14), 4388-4394.

[16]. Li, H. B., Cheng, K. W., Wong, C. C., Fan, K. W., Chen, F., \& Jiang, Y. (2007). Evaluation of antioxidant capacity and total phenolic content of different fractions of selected microalgae. Food chemistry, 102(3), 771-776.

[17]. Hadnađev, T. D., Hadnađev, M., Pojić, M., Rakita, S., \& Krstonošić, V. (2015). Functionality of OSA starch stabilized emulsions as fat replacers in cookies. Journal of Food Engineering, 167, 133-138.

[18]. Lara, E., Cortés, P., Briones, V., \& Perez, M. (2011). Structural and physical modifications of corn biscuits during baking process. LWT-Food Science and Technology, 44(3), 622630.

[19]. Chung, K. T., Wong, T. Y., Wei, C. I., Huang, Y. W., \& Lin, Y. (1998). Tannins and human health: a review. Critical reviews in food science and nutrition, 38(6), 421-464. 